\title{
EMERGENCY ROUTES IN ONE SHED IN CASE OF SINISTER
}

\section{Willan Almeida da Silva ${ }^{1}$, David Barbosa de Alencar ${ }^{2}$, Ricardo Silva Parente ${ }^{3}$, Jorge de Almeida Brito Junior ${ }^{4}$ and Camily Murrieta Vasconcelos Oliveira Bezerra ${ }^{5}$}

\author{
${ }^{1}$ Blauro Cardoso de Mattos Higher Education Institute - FASERRA. Manaus-Amazonas, Brazil. \\ 2, 3,4 Galileo Institute of Technology and Education of the Amazon - ITEGAM. Manaus-Amazonas, Brazil. \\ ${ }^{5}$ Nilton Lins University. Manaus-Amazonas, Brazil.
}

Email: willanas18@gmail.com, david002870@hotmail.com, ricardosilvaparente@ gmail.com, jorge.brito@itegam.org.br, camilymv@hotmail.com

Received: Aug 23th 2019

Accepted: Aug 30th 2019

Published: December 02 ${ }^{\text {th }}, 2019$

Copyright @2016 by authors and Galileo Institute of Technology and Education of the Amazon (ITEGAM).

This work is licensed under the Creative Commons Attribution International License (CC BY 4.0).

https://creativecommons.org/licen ses/by/4.0/

\section{Opea Aecen:}

\section{INTRODUTION}

The escape route is the route to be followed in case of urgent need to evacuate a site due to fire, landslides or other emergencies. For all workers or visitors to a particular location to feel safe in an emergency, it is important to know the escape route. Knowing the way forward at critical moments makes it easy for everyone to get out and save.

This paper will show an example of escape routes for a new shed, planning it. Many consider the planning of escape routes unnecessary because they claim that it is only leaving the entrances or exits of buildings, but all planning in a project is essential for the perfect functioning of an entire set.

Currently, companies, especially from the industrial hub, are investing considerably in security. And including in this context are the escape routes. Which assist in the removal, evacuation, of people within an establishment, so that there are no deaths in a claim.

The overall objective of this paper is to propose emergency signaling in a new warehouse in a district factory. Specifically, corridors and shed access areas will be checked to report key risk areas and demonstrate possible escape routes.

\section{LITERATURE REVISION}

\section{II.1 THE IMPORTANCE OF ESCAPE ROUTES}

Fire safety measures, as well as any other safety measures, may be preventive or protective. [1] defines these measures as follows:

Fire prevention measures are those associated with the fire prevention precaution and are intended solely to prevent the onset of fire, i.e. to control the risk of fire onset.

Fire protection measures are those designed to protect human life and property from the harmful effects of the fire already developing in the building. They are necessary for the overall fire safety system as the preventive measures fail to allow the fire to arise. These measures comprise the following elements of the overall system: limitation of fire growth; initial fire extinguishing; fire propagation limitation; precaution against propagation between buildings; safe evacuation of the building; precaution against structural collapse; and speed, efficiency and safety of combat and rescue operations [2].

Escape routes are the routes people should follow in case of accidents requiring evacuation. More than having signposts, a company must follow the requirements so that instructions are clearly and easily understood. 
To put it clearly, we cite the example of the Kiss nightclub, which for lack of clarity in escape routes, many people rushed to locked doors [3]. In short, escape routes are the planned, mapped, and detailed way for people to leave safely, quickly, and with good flow.

That's why it's important to keep your entire system up to date and have high performance devices. Thus, the combination of these methods and practices are really significant for protecting lives, buildings and heritage.

A fire prevention system is made up of a number of important equipment and devices predetermined by law [4]. But in order for it to prove useful, it must also have another indispensable element.

Escape routes are sometimes overlooked as many people find that the material part of the system is sufficient [5]. However, it is vital for saving lives and making the firefighting process faster and more efficient.

In a fire situation, it is normal for panic to spread. Therefore, when using escape routes, it is essential to try to use them in the correct way so as not to harm others who also need to pass them.

The emergency exit is the properly protected path, part of the escape route, to be traveled by the user of a building in case of fire, until reaching the public road or open space protected in communication with it [6].

The lack of evacuation route indicators may lead to panic situations in emergencies, where the tranquility factor is paramount for the prevention of major accidents.
The planning of the Escape Route should be well elaborated, taking into consideration: The MTB NR-23 guidelines; NBR 9077 and 13434; State Code for Fire Prevention; others that will make it easier for individuals to leave the affected places.

"The reliability of this element must necessarily be higher than that of the other system elements, since in the event of a fire occurring, endangering the safety of building users, meaning that other system elements have failed, the safe evacuation of the building will not may fail. It is therefore the most important element and most directly associated with the safety of human life in the event of fire" [7].

\section{II.2 SIGNALING WAYS}

Illustrated and [8] and can be seen in table 01 .

Circular: Used to deploy prohibition and command action symbols; Triangular: Used to deploy warning symbols; Square and Rectangular: Used to deploy guidance, distress, emergency and identification symbols for firefighting and alarm equipment;

Security Colors: The security color must cover at least $50 \%$ of the symbol area, except for the prohibition symbol, where this value must be at least 35\%; Red: Used for prohibition and identification symbols for firefighting and alarm equipment; Green: Used for guidance and distress symbols; Black: Used for warning symbols and danger signs; Contrast Colors: Contrast colors are white or yellow for prohibition and alert signaling respectively. Contrast colors shall be photoluminescent for orientation and equipment signaling.

Table 1: Signpost Dimensions 1.

\begin{tabular}{|c|c|c|c|c|c|c|c|c|c|c|c|c|c|}
\hline \multirow{2}{*}{ Signal } & \multirow{2}{*}{ Geometric form } & \multirow{2}{*}{ Share $\mathrm{mm}$} & \multicolumn{11}{|c|}{ Maximum distance of visibility $m$} \\
\hline & & & 4 & 6 & 8 & 10 & 12 & 14 & 16 & 18 & 20 & 24 & 28 \\
\hline Prohibition & & $\mathrm{D}$ & 101 & 151 & 202 & 252 & 303 & 353 & 404 & 454 & 505 & 606 & 706 \\
\hline Alert & & $\mathrm{L}$ & 136 & 204 & 272 & 340 & 408 & 476 & 544 & 612 & 680 & 816 & 951 \\
\hline Guidance, & & $\mathrm{L}$ & 89 & 134 & 179 & 224 & 268 & 313 & 358 & 402 & 447 & 537 & 626 \\
\hline Equipment & $\stackrel{\mathrm{L}}{\Downarrow} \underset{\forall}{\hat{H}}$ & $\begin{array}{c}\mathrm{H} \\
(\mathrm{L}=2 \mathrm{H})\end{array}$ & 63 & 95 & 126 & 158 & 190 & 221 & 253 & 285 & 316 & 379 & 443 \\
\hline
\end{tabular}

Source: Adapted from [8].

Table 2: Minimum height of letters on signposts as a function of reading distance.

\begin{tabular}{|c|c|c|c|}
\hline Minimum height mm & High impact reading distance (m) & Minimum height (mm) & High impact reading distance (m) \\
\hline 30 & 4 & 300 & 36 \\
\hline 50 & 6 & 350 & 42 \\
\hline 65 & 8 & 400 & 48 \\
\hline 75 & 9 & 500 & 72 \\
\hline 85 & 10 & 600 & 84 \\
\hline 100 & 12 & 700 & 90 \\
\hline 135 & 16 & 750 & 96 \\
\hline 150 & 18 & 800 & 108 \\
\hline 200 & 24 & 900 & 120 \\
\hline
\end{tabular}

Source: Adapted from [8]. 


\section{II.2.1 SIGNALING WAYS}

Orientation signs shall be as follows:

a) shape: square or rectangular;

b) background color (safety color): green;

c) symbol color (contrast color): photoluminescent;

d) margin (optional): photoluminescent.

\section{II.3 SIGNALING SYMBOLS}

The symbols adopted by this part of [8] for fire and panic signaling are presented in 3 , accompanied by application examples.

Table 3: Guidance and rescue signs.

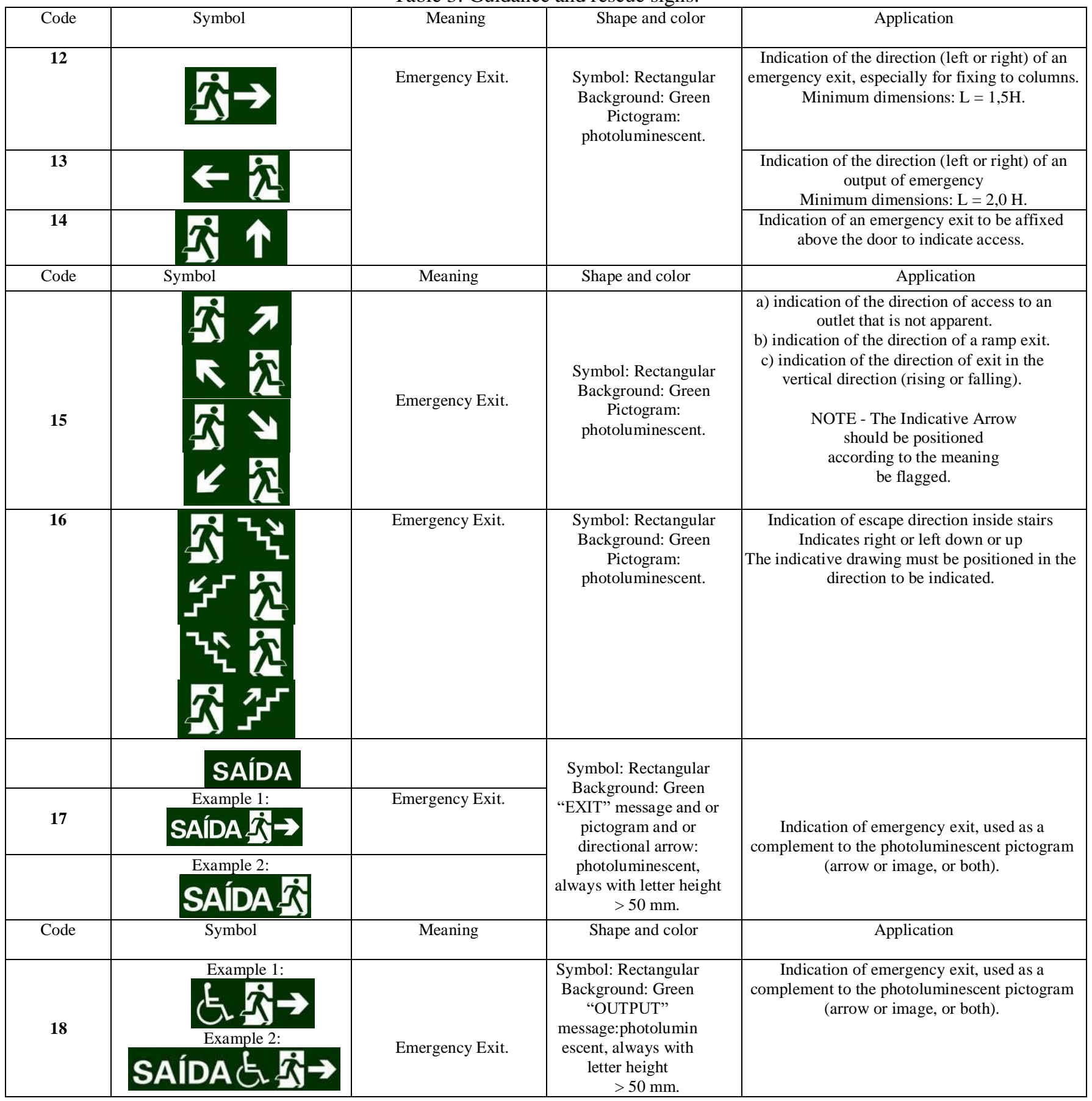

Source: Adapted from [8].

\section{II.3.1 CONTINUED INDICATION OF ESCAPE ROUTES}

Continued indication of escape routes shall be carried out by means of indicative arrows in accordance with the criteria specified in ABNT NBR 13434-1, installed in the direction of exit, with the following minimum shape, size and color specifications:
Table 4: Direction of exit route.

\begin{tabular}{|c|c|c|c|}
\hline Code & Symbol & Meaning & Shape and color \\
\hline 28 & & $\begin{array}{c}\text { Direction of } \\
\text { exit route. }\end{array}$ & $\begin{array}{c}\text { Symbol: Rectangular } \\
\text { Background: Green } \\
\text { Pictogram: } \\
\text { photoluminescent. }\end{array}$ \\
\hline
\end{tabular}

Source: Adapted from [8]. 
Emergency exits consist of doors, corridors, stairs, ramps or combinations of these elements, aiming at the safe escape of people from a building in the event of fire to the outside, as well as facilitating access by the Fire Department to the building. firefighting and rescue actions.

\section{MATERIALS AND METHODS}

The methodology used was through a work safety engineering project with the decision to develop a map of escape routes in case of emergency or accident in a warehouse in the motorcycle factory of the industrial hub of Manaus, with the purpose of to create escape routes correctly thus improving the evacuation of people from inside the shed and minimizing the risk of death or accident in case of emergency.

\section{STUDY APPLICATION \\ IV.1 LOCATION CHOICE}

For this work safety engineering project will be studied the new warehouse of a company of the industrial center of the city of Manaus - AM. The construction of this warehouse is due to the need to expand the factory, because it felt the need to increase its trade, thus having the reduced capacity to meet the production of parts.

The shed was built in a new area purchased by the company. It was done since its earthwork until the survey of the structure. Because it is a new sector. All security must therefore be done, including escape routes in case of emergency.

Looking at the industry floor plan to get an idea of where all signs should be placed. The idea of safety of the place is of great importance to the company, which invests heavily for the good of the employees and for the good of the company itself.

\section{IV.2 STUDY AREA LOCATION}

The area chosen for this study St. Jutaí 44569075-130, located in the city of Manaus Amazonas. Industrial District II, figure 1 .

The area was from another company and was purchased by this company in 2017, and since then, the shed was planned and started for its construction. Several companies are responsible for surveying the structure.

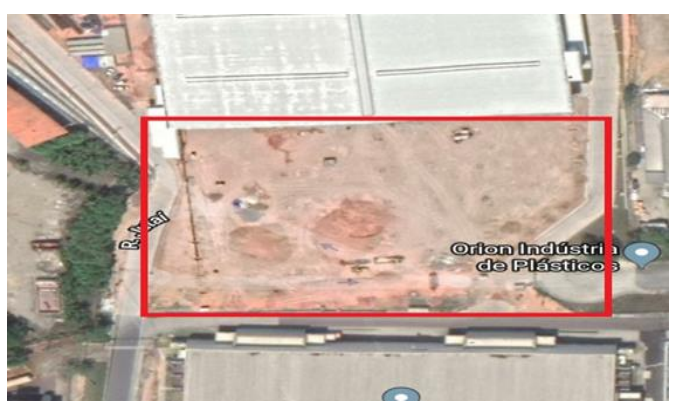

Figure 1: Area of study chosen. Source: [9].

From the outset the terrain was good, but for the dimensions of the project, it was necessary to make changes to the terrain to achieve satisfactory results.

Currently, the building is in the process of being completed, it was during this period that it was necessary to think about safety means for this area. As one of the key assets are employees, schemes and strategies have been put in place to keep safety in the first place. The escape routes are just a shame part of the great work ahead.

\section{IV.3 STUDY SITE IDENTIFICATION}

The study site chosen was fine in the city of Manaus - AM and it was from observations made about places that there is viability to take the route. After days of observation I could see the possible places where there is need and also it is feasible to put the safety signs.

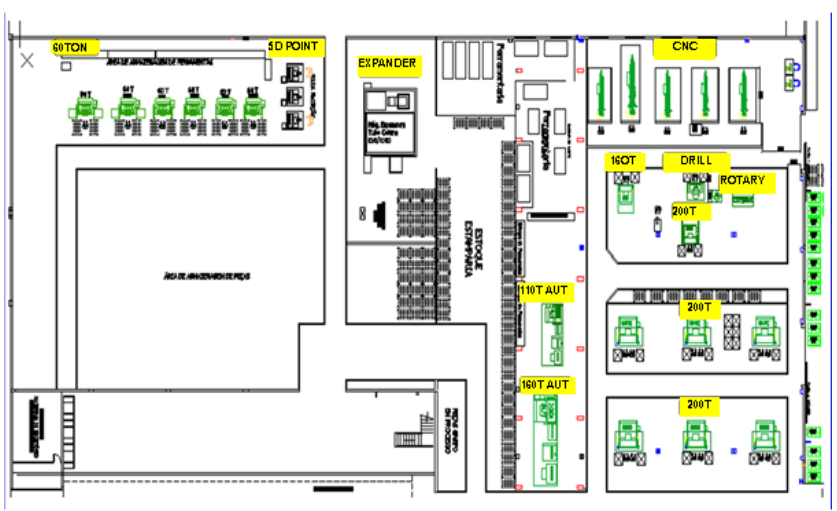

Figure 2: Plant image of the new shed being built. Source: Authors, (2019).

\section{RESULTS AND DISCUSSIONS}

We had a lot of debate about the escape route suggestions. Two of these suggestions were not welcomed by professionals in the area, below we can see:

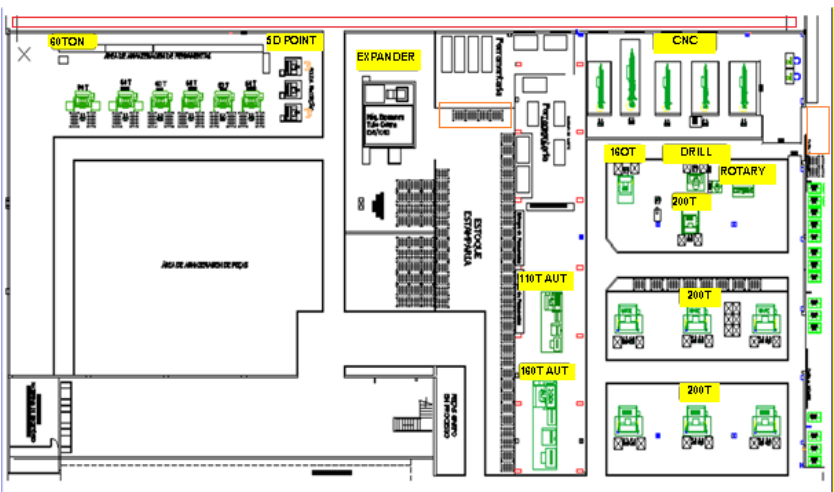

Figure 3. Shed image with demarcated locations. Source: Authors, (2019).

In the area marked in red it was not possible to make the project because this site will be made available for gas and water pipes, so it would be very dangerous to make the route in this area, as it would have a high risk of explosion.

On the other hand, the orange areas are not viable as it is intended for deposits of parts and equipment of the sector, therefore, the place will be obstructed thus preventing the traffic of people in the place.

\section{V.1 VERIFICATION OF THE VIABILITY OF THE SIGNS TO BE PUT}

After much study, we obtained the verdict of the speeches, see below how it looked: 


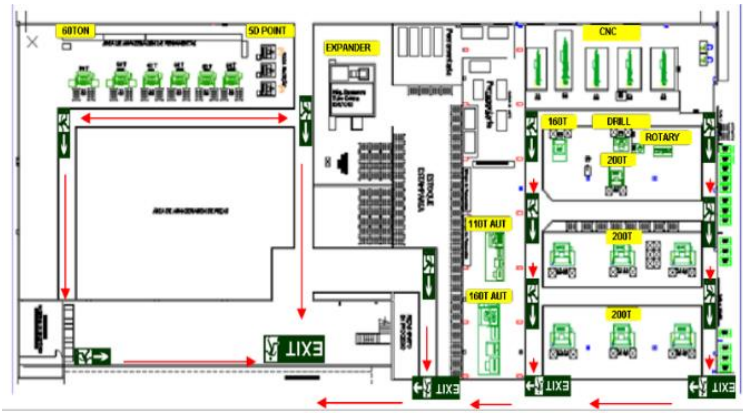

Figure 4: Result of escape route signs in the shed. Source: Authors, (2019).

We demonstrated the route that people will use in case of emergencies. We use the main corridors in the sector as there is a greater possibility of mobility, therefore, free of obstacles or obstructions in the path of the emergency route.

\section{CONCLUSIONS}

Escape routes play a very important role in any building as they are directly linked to the safety of the site, and hence of the individuals within the site.

Most of the companies in the Manaus Industrial Pole are investing a lot in security, which is why this type of project has grown considerably. Maintaining a safe environment considerably influences the credibility of the company. Having visibility of the direction indicator plates is indispensable, because if it is not in visible conditions, it is a design irregularity, thus having no functionality in the work environment.

Safety always comes first, and having safe evacuation sites is one of those principles.

\section{ACKNOWLEDGMENT}

To the educational institution Faserra, which has always done its best to provide comfort and the best teachers, providing the necessary knowledge for the realization of this project. and ITEGAM for supporting research.

\section{REFERENCES}

[1] Ono, Rosaria. Proteção do Patrimônio histórico-cultural contra incêndio em edificações de interesse de preservação. Palestra apresentada na Fundação Casa de Rui Barbosa. Rio de Janeiro, 2004.

[2] Sieben, Monique. Prevenção e segurança contra incêndio: legislação, normas e instruções técnicas para extração e controle de fumaça. 2014.

[3] Loutfi, Marcelo. Investigação do acidente da Boate Kiss em Santa Maria-Rio Grande do Sul-Brasil. 2015. PhD Thesis. Universidade de São Paulo.

[4] Gomes, Taís. Projeto de prevenção e combate a incêndio. Santa Maria, 2014.

[5] Machado, Euclides Tupinambé Silva. Segurança contra incêndio no ambiente hospitalar: estudo de caso no Hospital Universitário de Brasília-DF. 2018.

[6] Código de Obras E Edificações do Município de Santa Maria, 2009, p.59
[7] Braga, Luiz Antônio Fernandes. Simulação de Rota de Fuga e Sinalização Utilizando Multi-Agentes e Realidade Virtual. 2006. PhD Thesis. D. Sc. thesis, Universidade Federal do Rio de Janeiro.

[8] NBR 13434 - Sinalização de segurança contra incêndio e pânico - formas, dimensões e cores.

[9] Google Maps, 2019. 